\title{
Oxacillin coupled G-quadruplexes as a novel biofilm-specific antibiotic for Staphylococcus aureus biofilms
}

Renzo A. Fenati, ${ }^{\dagger}$ Katherine Locock ${ }^{\zeta}$, Yue Qu, ${ }^{,}$and Amanda V. Ellis ${ }^{*}{ }^{\dagger}$

†School of Chemical and Biomedical Engineering, Melbourne School of Engineering, The University of Melbourne, Parkville, Victoria 3010, Australia

$\zeta$ CSIRO Manufacturing, Clayton, Victoria 3168, Australia

* Department of Infectious Diseases, The Alfred Hospital and Monash University, Clayton, Victoria 3800, Australia

KEYWORDS. G-quadruplexes, biofilms, antibiotic, diffusion, peroxidase-mimicking, oxacillin

Corresponding Author

*Prof. Amanda V. Ellis

Email: Amanda.ellis@unimelb.edu.au 
ABSTRACT. One of the most important traits of pathogenic microbial biofilms is their high tolerance to conventional antimicrobial agents, which is partially due to the presence of metabolically inactive and transiently resistant persister cells. Here, we use guanine-rich DNA structures known as G-quadruplexes (G4s) coupled with the $\beta$-lactam antibiotic, oxacillin (OX), and loaded with an iron-containing protoporphyrin IX (hemin), as an OXG4/hemin complex biofilm-specific antibiotic agent. By coupling the OX to the G4, to form an OXG4/hemin complex, the diffusion of the OX was facilitated into the biofilm. Further, by utilizing the known oxidizing behavior (peroxidase-mimicking) of the G4/hemin complex the entire system was found to be highly effectively against Staphylococcus aureus biofilms. By using G4 structures to penetrate biofilms, this work paves the way for an entirely new DNA-based therapy for biofilm eradication.

\section{INTRODUCTION}

The rise of chronic infections has been linked to biofilms formed by many pathogenic microorganisms. ${ }^{1-5}$ Morphologically, biofilms are sessile cells (aggregated cells on a surface) embedded in a protective extracellular polymeric matrix that consist of polysaccharides, proteins and extracellular DNA (eDNA). ${ }^{6-11}$ The presence of metabolically inactive and transiently resistant persister cells within a biofilm in combination with low drug diffusion and subsequent sub-lethal antimicrobial dose levels across biofilms contribute to the genotypical development of antimicrobial resistance. ${ }^{12-14}$ Strategies to combat biofilm forming bacteria, and reduce the prevalence of chronic infections, have included the use of high concentrations, or combinations of, conventional antimicrobial agents. ${ }^{5,15}$ New biofilm-effective agents that target persister cells, or disrupt the biofilm structure, have also been investigated such as, nanoparticles (e.g., silver, ${ }^{16}$ gold $^{17}$ or palladium ${ }^{18}$ ) and enzymes $\left(\right.$ DNase $\left.^{19}\right)$. 
More recently, thiocyanate (SCN)-peroxidase-hydrogen peroxide $\left(\mathrm{H}_{2} \mathrm{O}_{2}\right)$ treatments have been explored. ${ }^{20}$ In this treatment the peroxidase enzyme reacts with $\mathrm{H}_{2} \mathrm{O}_{2}$ which then oxidizes the SCN. The oxidized thiocyanate then damages the essential structural and functional components of the bacteria cells, inhibiting their growth and eventually killing the cells. This approach has had success at eliminating planktonic bacteria but is yet to be tested on sessile bacteria within a biofilm. Further, SCN can be toxic and known to affect the thyroid and hormonal function, particularly in patients with reduced renal function. Thus, the $\mathrm{SCN}$-peroxidase- $\mathrm{H}_{2} \mathrm{O}_{2}$ system has somewhat limited effectiveness as an antimicrobial system within the human body. ${ }^{20,21}$

A potential method to replace the $\mathrm{SCN}$-peroxidase $-\mathrm{H}_{2} \mathrm{O}_{2}$ system is to use the peroxidasemimicking activity of catalytic DNA molecules (DNAzymes), in particular G-quadruplexes (G4s) which provide several advantages over enzymes; including cheaper synthesis and purification, wider operating conditions ( $\mathrm{pH}$ and temperature) and the ability to react with a various substrates. ${ }^{22,23} \mathrm{G} 4 \mathrm{~s}$ are assembled from guanine-rich (G-rich) DNA sequences that can stack two or more guanine-quartets (G-quartets) (see Figure 1(a)) in the presence of a metal cation. ${ }^{24}$ Once assembled, the G4s can take on several conformations including parallel, anti-parallel and hybrid (see Figure 1(a)) and can be composed of a single DNA strand (intramolecular) or multiple DNA strands (intermolecular). ${ }^{25,26}$

Of particular interest is that G4s are able to complex with hemin (Figure 1(b)), an iron containing protoporphyrin IX, which acquires peroxidase-mimicking activity in the presence of $\mathrm{H}_{2} \mathrm{O}_{2} \cdot{ }^{27}$ The hemin (FeIII) first complexes with $\mathrm{H}_{2} \mathrm{O}$, which is then replaced with $\mathrm{H}_{2} \mathrm{O}_{2}$ (Figure 1(c)). ${ }^{28}$ The peroxide is then broken down to form what is known as Compound I (a $\pi$ radical cation protoporphyrin $\left(\mathrm{FeIV}-\mathrm{O}^{++}\right)$). The FeIV $-\mathrm{O}^{++}$is then able to react with a substrate to form FeIV-O 
known as Compound II. ${ }^{26}$ Compound II can then be recycled back into hemin (pre-Compound I) or Compound I, therefore acting as a DNAzyme that can continuously react and regenerate. ${ }^{29}$

Importantly, from a diagnostic perspective, G4/hemin complexes in the presence of hydrogen peroxide are compatible with the well-established colorimetric peroxidase-based enzyme immunoassays (e.g., 3,3,5,5-tetramethylbenzidine (TMB; $\left.\lambda_{\mathrm{ABS}}=605 \mathrm{~nm}\right)^{30}$ and 2,2'-azino-bis(3ethylbenzothiazoline-6-sulphonic acid) (ABTS; $\lambda_{\mathrm{ABS}}=410 \mathrm{~nm}$ and $\left.650 \mathrm{~nm}\right)^{31}$. This allows the concentration of G4/hemin complexes to be detected at sub- $\mu \mathrm{M}$ levels with the extent of the reaction being based on the $\mathrm{H}_{2} \mathrm{O}_{2}$ concentration.

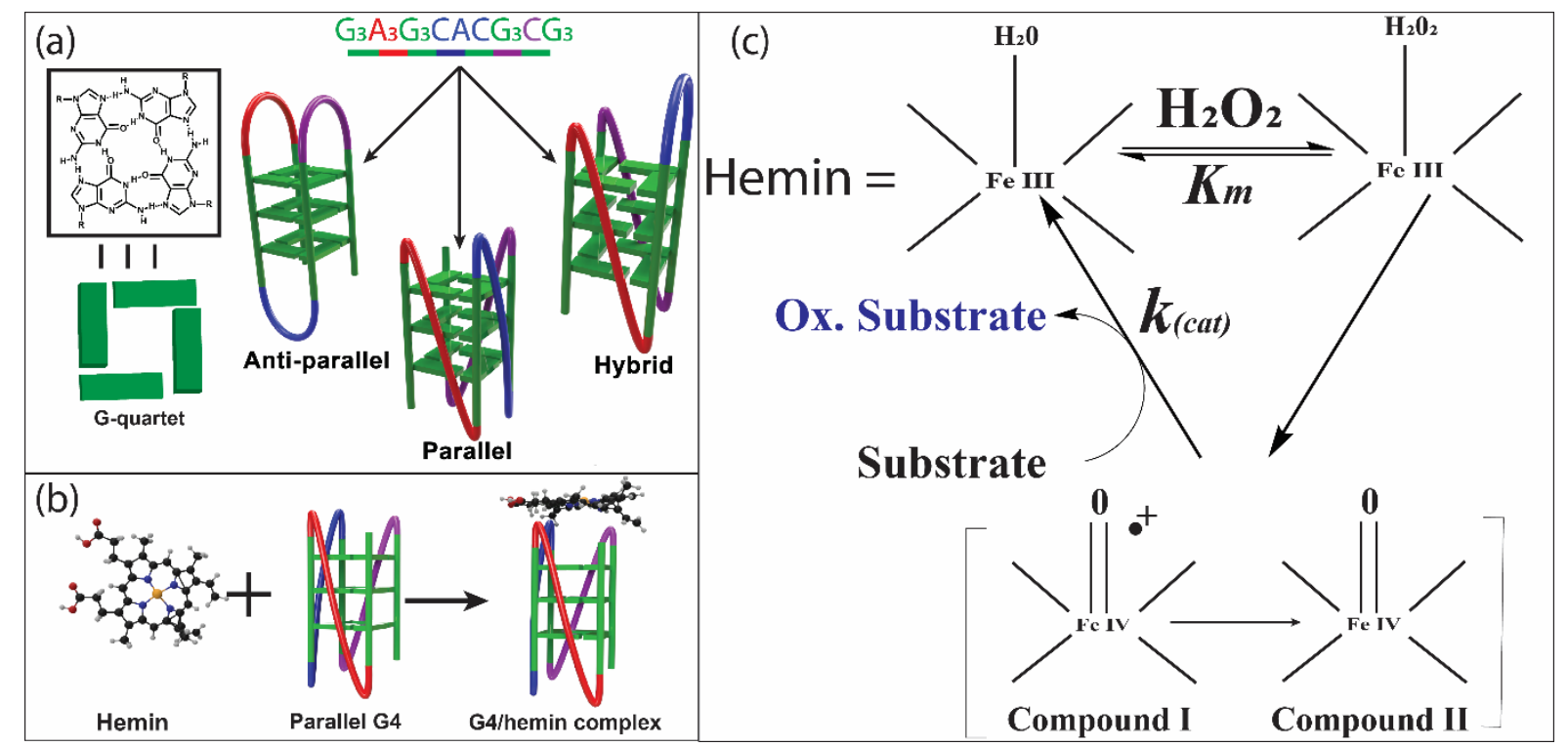

Figure 1. (a) Schematic of general G-quadruplex (G4) conformations; G-quartet, anti-parallel, parallel and hybrid (formed from a single or multiple G-rich DNA sequence), (b) Schematic of the formation of a hemin (iron-containing protoporphyrin) with a G4 to form a G4/hemin complex and (c) Schematic of generalized reaction of hemin peroxidase-mimicking activity. 
Given that G4/hemin complexes have been shown to have a wider range of reactants compared to peroxidase enzymes, but narrower than thiocyanate, in this work we use G4/hemin complexes as a possible method for eradication of biofilm bacteria. ${ }^{32}$ One of the important considerations is getting the complexes across the biofilm. Another route of interest is using the these G4/hemin complexes in conjunction with antibiotics. Many drugs are able to easily penetrate biofilms (e.g., cefotaxime, amikacin), however the $\beta$-lactam antibiotic, oxacillin (OX) (Figure 2(a)), does not penetrate through Staphylococcus aureus biofilms at minimum inhibitory concentrations (MIC) of $1 \mu \mathrm{g} \mathrm{mL}{ }^{-1} \cdot{ }^{33}$ Therefore, by using OX coupled with the G4 complex may contribute to a synergistic killing affect.

Here, we detail a proof-of-concept peroxidase-mimicking system that utilizes G-rich DNA sequences chemically coupled with OX. These sequences are then folded into secondary threedimensional G4 structures in the presence of hemin for use as an antimicrobial agent against $S$. aureus American Type Culture Collection (ATCC) 29213 biofilms. The OX was calculated at 1

$\mu \mathrm{g} \mathrm{mL}^{-1}$ in the resulting OXG4/hemin structure. The G4/hemin structure was shown to penetrate the biofilms (acting as a diffusion facilitator) leading to the coupled OX having an antimicrobial effect within the biofilm construct.

\section{EXPERIMENTAL SECTION}

\subsection{Materials}

All chemicals were purchased from Sigma-Aldrich (USA) unless stated otherwise. A stock Tris-EDTA buffer (10X, pH 7.5) was made up by dissolving tris(hydroxymethyl) aminomethane 
(Tris) (15.8 g) and ethylenediamine tetraacetic acid (EDTA) (2.92 g, pH 8) in Milli-Q water (18.3 $\mathrm{M} \Omega \mathrm{cm})(1 \mathrm{~L})$ and adjusted to $\mathrm{pH}$ 7.5. Reaction buffer (10X) was made up by Tris (15.8 $\mathrm{g})$ and $\mathrm{KCl}(37.3 \mathrm{~g})$ in Milli-Q water $(1 \mathrm{~L})$ and adjusted to $\mathrm{pH}$ 7.5. 2-( $N$-morpholino)ethanesulfonic acid hemisodium salt (MES) buffer (1 $\mathrm{M}, \mathrm{pH}$ 4.5) was made up by dissolving 2-(Nmorpholino)ethanesulfonic acid $(195.2 \mathrm{~g})$ in Milli-Q water (1 L). The 3,3',5,5'tetramethylbenzidine (TMB) Liquid Substrate System was used for the determination of peroxidase-mimicking activity. Mueller-Hinton broth (MHB) and Mueller-Hinton agar (MHA) was made according to the manufacturer's recommendations using reverse osmosis (RO) water, autoclaved at $121{ }^{\circ} \mathrm{C}$ for $10 \mathrm{~min}$ and stored at $4{ }^{\circ} \mathrm{C}$. Bovine serum albumin (BSA) was used as purchased. S. aureus ATCC 25923 (non-biofilm forming ${ }^{33}$ ) and S. aureus ATCC 29213 (biofilm forming ${ }^{33}$ ) bacterial strains were purchased from ATCC, Inc., USA and stored at $4{ }^{\circ} \mathrm{C}$ on MHB agar plates. Table 1 shows the oligodeoxynucleotide (ODN) sequence (and melting temperature) used to form the G4 structures as well as the sequence used for coupling oxacillin.

Table 1. Sequences and melting temperatures of oligodeoxynucleotides (ODNs) used for fabricating G-quadruplexes (G4s) (the G4 ODN), including the sequence used for coupling with oxacillin $\left(\mathrm{NH}_{2} \mathrm{G} 4 \mathrm{ODN}\right.$, tagged with the fluorophore $\left.\mathrm{Cy} 3.5\right)$. G4 structure forming sequences are labelled in bold.

Sequence $^{\alpha} 5^{\prime} \Rightarrow 3^{\prime}$

G4 ODN

$\mathrm{G}_{3} \mathrm{~A}_{3} \mathrm{G}_{3} \mathrm{CAC}_{2} \mathrm{G}_{3} \mathrm{C}_{2} \mathrm{G}_{3}$

$\mathrm{NH}_{2} \mathrm{G} 4$ ODN

$\mathrm{NH}_{2}-\mathrm{ATGA}_{2} \mathrm{~T}_{3} \mathrm{C}_{2} \mathbf{G}_{3} \mathbf{A}_{3} \mathbf{G}_{3} \mathbf{C A C}_{2} \mathbf{G}_{3} \mathrm{C}_{2} \mathrm{G}_{3} \mathrm{CACAC}_{2} \mathrm{~A}-\mathrm{Cy} 3.5$ 
The G4 ODN was unlabeled while the $\mathrm{NH}_{2} \mathrm{G} 4$ ODN was tagged at the 3 ' end with the fluorophore CY3.5 for concentration determination. All ODNs were purchased from IDT DNA (USA), made up to $100 \mu \mathrm{M}$ and stored at $4{ }^{\circ} \mathrm{C}$.

\subsection{Oxacillin coupling to the $\mathrm{NH}_{2} \mathrm{G} 4$ ODN}

The antibiotic, OX was coupled to the $\mathrm{NH}_{2} \mathrm{G} 4$ ODN (see Table 1 for sequence). This was achieved by coupling the carboxylic acid functional group on $\mathrm{OX}$ to the amine functional group on the $\mathrm{NH}_{2} \mathrm{G} 4$ ODN using 1-ethyl-3-(3-dimethylaminopropyl)carbodiimide (EDC) coupling. Briefly, the $\mathrm{NH}_{2} \mathrm{G} 4$ ODN $(5 \mu \mathrm{M}, 5 \mu \mathrm{L})$ was added to excess $\mathrm{OX}(15 \mu \mathrm{M}, 45 \mu \mathrm{L})$ in $0.1 \mathrm{M}$ MES buffer and vortexed for $60 \mathrm{~s}$. EDC (20\% (w/v), $50 \mu \mathrm{L})$ in $0.1 \mathrm{M}$ MES buffer was then added to the $\mathrm{NH}_{2} \mathrm{G} 4 \mathrm{ODN}$ and $\mathrm{OX}$ mixture and vortexed for a further $60 \mathrm{~s}$. The mixture was placed in a thermomixer at $25^{\circ} \mathrm{C}$ for $20 \mathrm{~min}$ with alternating cycles of $30 \mathrm{~s}$ shaking $(1400 \mathrm{rpm})$ and $30 \mathrm{~s}$ of standing. The resulting antibiotic attached ODN was denoted OXG4. DNA ethanol precipitation was performed to purify the OXG4. ${ }^{36}$ The concentration of the precipitated OXG4 was determined using a standard curve carried out on a RotoGene Q 6-plex real-time polymerase chain reaction thermocycler (Qiagen, Germany). ${ }^{37}$ By determining the concentration of the DNA, assuming $100 \%$ attachment of the $\mathrm{OX}$ to the $\mathrm{NH}_{2} \mathrm{G} 4 \mathrm{ODN}$, it was possible to determine the concentration of the OX present on the DNA.

\subsection{Folding of G4 and G4/hemin structures}

The concentrations of the as supplied ODNs (see Table 1 for sequences) were measured using a Nanodrop 2000 and then diluted down to $50 \mu \mathrm{M}$ in a Tris-EDTA buffer (1X). For the formation of the all G4 structures in this article the following procedure was followed: each G4 ODN and $\mathrm{NH}_{2} \mathrm{G} 4$ ODN $(50 \mu \mathrm{M}, 4 \mu \mathrm{L})$ was diluted in Reaction buffer $(32 \mu \mathrm{L})$ containing $\mathrm{K}^{+}$ions $(50 \mathrm{mM})$. 
Each solution was placed in a thermocycler and first heated to $95^{\circ} \mathrm{C}$ then cooled to $30{ }^{\circ} \mathrm{C}$ over a 30 min time period. In order to prevent the OX from degrading at high temperatures the OXG4 was placed in Reaction buffer (final concentration of $10 \mu \mathrm{M}$ and left at room temperature for 30 $\min .{ }^{38}$ The folded OXG4 structure was confirmed using the TMB assay described below.

\subsection{TMB assay}

In order to measure the peroxidase-mimicking activity of the folded G4, G4/hemin, OXG4, OXG4/hemin structures a TMB assay was performed. First, each solution $(5 \mu \mathrm{M}, 5 \mu \mathrm{L})$ was added to a 96-well plate. TMB Liquid Substrate solution $(195 \mu \mathrm{L})$ was added to each well. The 96-well plate was then placed in a FLUOstar Omega microplate reader (BMG Labtech, Germany) and the absorbance measured at $605 \mathrm{~nm}$ every $30 \mathrm{~s}$ for $10 \mathrm{~min}$. The results where then analyzed using an OriginPro 9.0 software linear fit function to determine the slope of each curve. Initial velocity $\left(\mathrm{V}_{0}\right.$ of the reaction was determined using a modified Beers Law Equation (Eq. 1):

$$
V_{0}=\frac{A}{\varepsilon}
$$

Where $\mathrm{A}$ is the measured absorbance and $\varepsilon$ is the molar extinction of TMB $+\left(39,000 \mathrm{~L} \mathrm{~mol}^{-1}\right.$ $\left.\mathrm{cm}^{-1}\right)$.

2.5 Minimum inhibitory concentration (MIC)

The MIC was determined using the serial dilutions method set out in the Clinical and Laboratory Standards Institute (CLSI) and performed in aseptic conditions. ${ }^{29}$ The bacteria used for this MIC determination was S. aureus ATCC 25923 (non-biofilm forming for MIC tests), which is susceptible to methicillin antibiotics such as OX. Both OX and the OXG4 were tested. OX was diluted from a stock solution $\left(10240 \mu \mathrm{g} \mathrm{mL}^{-1}\right)$ to $8.0,4.0,2.0,1.0,0.5,0.25$ and $0.125 \mu \mathrm{g} \mathrm{mL}^{-1}$. 
The OXG4 was diluted to $10.000,5.000,2.500,1.250$ and $0.625 \mu \mathrm{M}$ which is equivalent to 4.000, $2.000,1,000,0.500$ and $0.250 \mu \mathrm{g} \mathrm{mL} L^{-1}$ of coupled antibiotic, based on a molecular weight of $401.436 \mathrm{~g} / \mathrm{mol}$ of OX. This will result in a final concentration of $2.000,1.000,0.500,0.250$ and $0.125 \mu \mathrm{g} \mathrm{mL}^{-1}$ of coupled antibiotic when determining the MIC. The OX and OXG4 serial dilutions (20 $\mu \mathrm{L}$ ) were added to 96 -well plates (ignoring the first column and row) and $20 \mu \mathrm{L}$ of $5 \times 10^{5} \mathrm{~S}$. aureus cells in MHB. Visual inspection was used to determine if any bacterial growth was successful. The only modification of the CLSI standard procedure was the use of flat bottomed 96well plates as opposed to round bottom well plates. This has been previously published as an acceptable modification. ${ }^{39}$

2.6 Biofilm growth in 96-well plates

Biofilms were grown by preparing a cell suspension of S. aureus ATCC 29213 (biofilm forming) in MHB (50 $\mu \mathrm{L})$ that was then added into $3 \times$ x 96 -well plates (ignoring the first column and row) and incubated at $37^{\circ} \mathrm{C}$ for 90 min, shaking at $75 \mathrm{rpm}$. Afterwards the cell suspension was removed and MHB (1 mL) was replaced and the 96-well plates further incubated for $24 \mathrm{~h}$ at $37^{\circ} \mathrm{C}$, with shaking at $75 \mathrm{rpm}$. The 96-well plates were then washed with PBS solution to remove planktonic cells. One 96-well plate was used to determine the CFU of the biofilms. The two remaining 96-well plates were used for CV staining. These 96-well plates were dried upside down at $60{ }^{\circ} \mathrm{C}$ for $1 \mathrm{~h}$ prior to use.

The drop plate method was used to evaluate the CFU of the bacteria in the 96-well plates. ${ }^{8}$ Briefly, PBS solution $(50 \mu \mathrm{L})$ was added to each well that contained a S. aureus ATCC 29213 biofilm. Then the biofilm was scratched off using a plastic pipette tip. This was performed 3 times for each well to ensure all the biofilm was removed. The PBS solution, with scratched off biofilm 
from each well, was then placed in separate Eppendorf tubes and vortexed for 2 min with subsequent sonication for 10 min to break apart the biofilm. Each sample was diluted 10-fold eight times. Each dilution $(10 \mu \mathrm{L})$ was pipetted onto a horizontal MHA plate and the plate was lifted vertically to allow for the drop to run down the plate. The plates were incubated at $37^{\circ} \mathrm{C}$ for $20 \mathrm{~h}$. All the spots on each plate were counted, one spot was equivalent to $1 \mathrm{CFU}$, and multiplied by the dilution factor.

\subsection{Biofilm growth on silicone coupons}

In order to determine the successful growth of biofilm, sterilized silicone coupons (BioSurface Technologies Corporation, USA) that had been incubated in bovine serum albumin (BSA) overnight, were used. The coupons were placed into a 12-well plate (ignoring the first column and row) with a cell suspension ( 5 x $10^{5}$ cells) of $S$. aureus ATCC 25293 in MHB ( $\left.1 \mathrm{~mL}\right)$ and incubated at $37{ }^{\circ} \mathrm{C}$ for $90 \mathrm{~min}$, with shaking at $75 \mathrm{rpm}$. Afterwards the cell suspension was removed and the MHB (1 mL) was replaced. The plate was further incubated for $24 \mathrm{~h}$ at $37{ }^{\circ} \mathrm{C}$, with shaking at 75 rpm. The silicone coupons are then removed and placed into PBS solution and vortexed for 5 min to remove any planktonic cells and then stained using a LIVE/DEAD ${ }^{\mathrm{TM}}$ BacLight $^{\mathrm{TM}}$ Bacterial Viability Kit for $40 \mathrm{~min}$. The coupons were washed with PBS solution and analyzed using a Confocal TCSPC fluorescence scanning microscope (CFSM) with a 100x objective. Blue and yellow excitation with SYTO 9 stain and propidium emission filters were used to detect the staining.

\section{RESULTS AND DISCUSSION}


The ODN sequences used to prepare both a G4/hemin complex and an OX coupled G4 (OXG4) complex are shown in Table 1. The G4 ODN selected for coupling with the OX was a Cy3.5 fluorophore (Figure 2(b)) tagged $\mathrm{NH}_{2} \mathrm{G} 4$ ODN sequence. This only differs from the G4 ODN by a spacer region of 6 nucleotides residues on either side of the G4 sequence to limit steric interaction of the fluorophore during folding. The coupling of the $\mathrm{OX}$ to the $\mathrm{NH}_{2} \mathrm{G} 4$ ODN was carried out using 1-ethyl-3-(3-dimethylaminopropyl)carbodiimide (EDC).

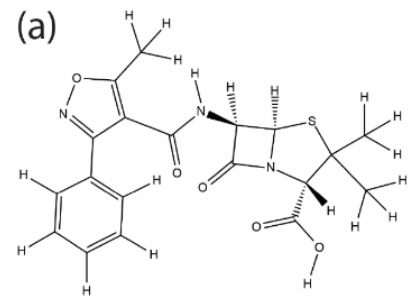

Oxacillin (b)

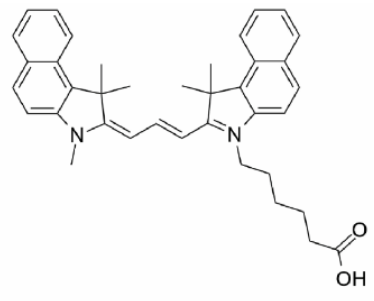

Cy3.5

Figure 2. Chemical structures (a) oxacillin (OX) and (b) the fluorophore Cy3.5.

Confirmation of $\mathrm{OX}$ coupling to the $\mathrm{NH}_{2} \mathrm{G} 4$ ODN was performed using polyacrylamide electrophoresis (PAGE), shown in Figure 3. The $\mathrm{NH}_{2} \mathrm{G} 4$ shows a mixture of single stranded ODNs and folded intramolecular G4 structures at approximately 27 nts. ${ }^{34}$ The upper brighter band is a result of intermolecular (bimolecular) G4 structures at approximately 34 nts. ${ }^{34}$ Once OX was coupled to the $\mathrm{NH}_{2} \mathrm{G} 4$ an increase in the molecular weight was observed, indicating successful attachment. The intramolecular structures are still observed but now at a slightly higher molecular weights, at approximately $28 \mathrm{nts}$, and the intermolecular structures were likewise slightly increased at approximately $35 \mathrm{nts}$. 


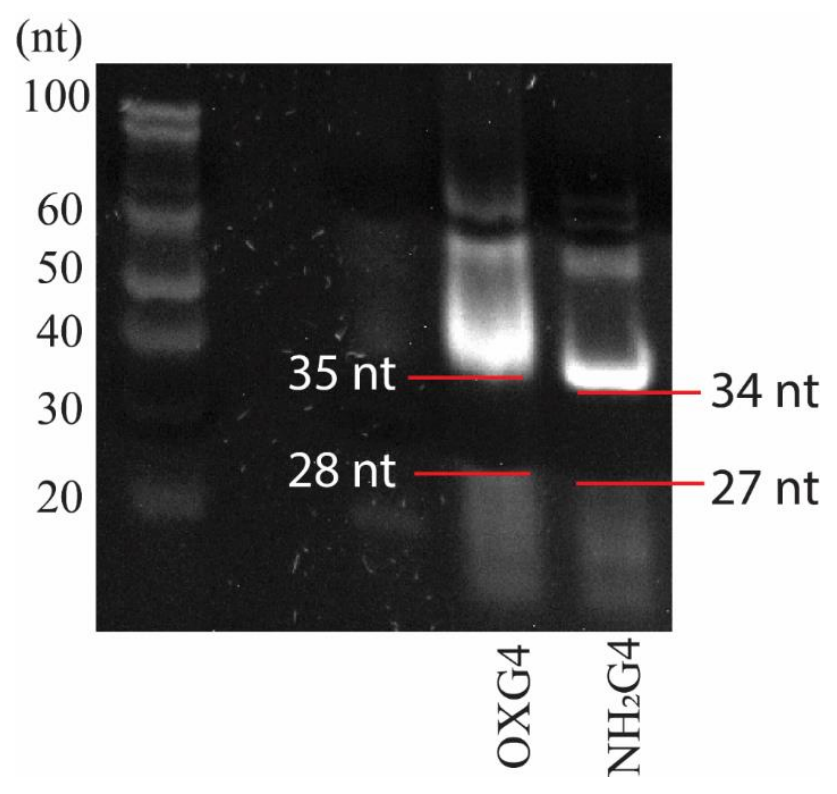

Figure 3. PAGE $12 \%$ (v/v) electrophoretogram of folded $\mathrm{OXG} 4$ and $\mathrm{NH}_{2} \mathrm{G} 4$ ODNs, stained with 1X SYBR Green I and viewed using a Gel Doc. A DNA Ladder (20/100 Ladder Oligo length standards) was used for reference. The red lines indicate bands of interest with the approximate weights.

In order to determine if there were any negative effects caused by coupling the ODN with OX, such as loss of antimicrobial or peroxidase-mimicking activity, TMB assays and MIC assays were performed. First, a TMB assay was performed to determine the peroxidase-mimicking activity of the folded DNA structures with and without coupled OX. Figure 4 shows the plot of $\mathrm{TMB}^{+}$ concentration $(\mu \mathrm{M})$ versus time (s) results of the TMB assay for hemin (control with no G4, green overlapping blue line), G4/hemin (black), NH2G4/hemin (pink), OXG4/hemin (red) and OX/hemin (no G4, blue). All samples have hemin at $8 \mu \mathrm{M}$. The initial peroxidase-mimicking activity $\left(\mathrm{V}_{0}\right)$ calculated from the data is shown in Table 2. 


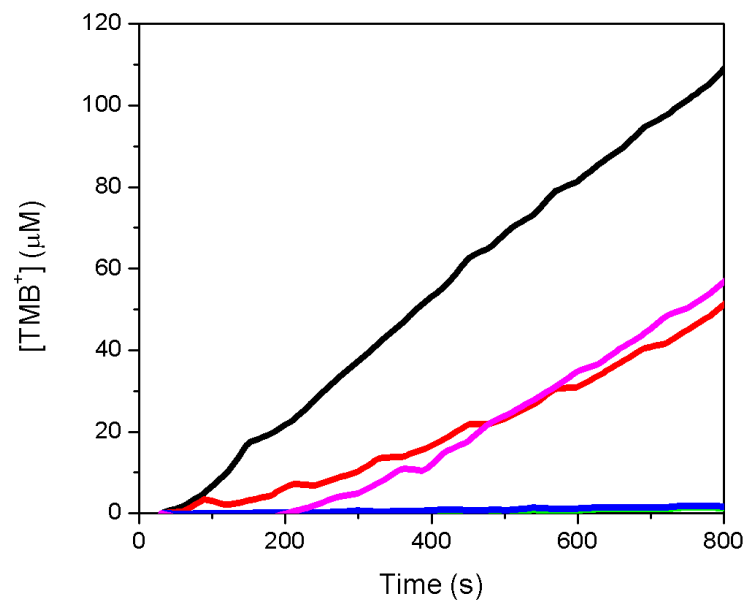

Figure 4. TMB assay. Plot of $\mathrm{TMB}^{+}$concentration $(\mu \mathrm{M})$ versus time (s); hemin (control with no G4, green), G4/hemin (black), $\mathrm{NH}_{2} \mathrm{G} 4 /$ hemin (pink), OXG4/hemin (red) and OX/hemin (no G4, blue). The data are an average of three UV/visible spectra calculated using the OriginPro 9.0 average curve function.

The G4/hemin complex had the highest $V_{0}$ at $0.204 \mu \mathrm{M} \mathrm{s}^{-1}$ compared to the $\mathrm{NH}_{2} \mathrm{G} 4 /$ hemin complex with a $\mathrm{V}_{0}=0.130 \mu \mathrm{M} \mathrm{s}^{-1}$ (Table 2). This inhibition of the peroxidase mimicking activity by the $\mathrm{NH}_{2} \mathrm{G} 4 \mathrm{ODN}$ is likely due the additional functionalities (Cy3.5 fluorophore and spacer region (nucleotide residues)) in the structure compared to the G4 complex on its own.

After coupling of $\mathrm{OX}$ to the $\mathrm{NH}_{2} \mathrm{G} 4$ a slight increase in the peroxidase-mimicking activity of the OXG4/hemin complex was observed $\left(\mathrm{V}_{0}=0.170 \mu \mathrm{M} \mathrm{s}^{-1}\right)$ compared to the $\mathrm{NH}_{2} \mathrm{G} 4 /$ hemin complex $\left(\mathrm{V}_{0}=0.130 \mu \mathrm{M} \mathrm{s}^{-1}\right)$. The difference in the peroxidase-mimicking activity between the $\mathrm{NH}_{2} \mathrm{G} 4 /$ hemin and $\mathrm{OXG} 4 /$ hemin complex is proposed to be due to a difference in the structure of the G4 complex formed. 
Table 2. Peroxidase-mimicking activity ( $\mathrm{V}_{0}$, calculated using Eq. 1) of TMB assay for hemin (control, no G4), G4/hemin, $\mathrm{NH}_{2} \mathrm{G} 4 /$ hemin, OXG4/hemin and $\mathrm{OX} /$ hemin (no G4). Data is calculated from Figure 4.

\begin{tabular}{cc}
\hline Sample & Peroxidase-mimicking activity, $\mathrm{V}_{0}$, \\
with hemin at $(8 \mu \mathrm{M})$ & $\mu \mathrm{M} \mathrm{s}^{-1},($ Error $=\leq 1 \%)$ \\
\hline hemin (control) & 0.001 \\
G4/hemin & 0.204 \\
$\mathrm{NH}_{2} \mathrm{G} 4 / \mathrm{hemin}$ & 0.130 \\
OXG4/hemin & 0.170 \\
OX/hemin (no G4) & 0.001 \\
\hline
\end{tabular}

Figure 5 shows the two possible conformations that the OXG4 with coupled OX (white ball) and Cy3.5 (yellow ball) can form in an intermolecular G4 structure. In the anti-parallel G4 conformation (Figure 5, top), the OX and Cy3.5 fluorophore are more likely to interact with each other and this can exert steric hinderance. This steric hindrance decreases the likelihood of the anti-parallel conformation forming. In the parallel G4 conformation (Figure 5, bottom), the OX and Cy3.5 are further spaced apart and therefore do not have the same steric hinderance as in the anti-parallel. Therefore, the parallel G4 conformation is favored and is well known to have higher peroxidase-mimicking activity than the anti-parallel G4 conformation (Cheng et al. ${ }^{27}$ ). However, for the $\mathrm{NH}_{2} \mathrm{G} 4$ (not coupled to $\mathrm{OX}$ ) no such steric hindrance occurs which allows more of the anti- 
parallel G4 conformation to form, resulting in the $\mathrm{NH}_{2} \mathrm{G} 4 /$ hemin complex possessing a lower $\mathrm{V}_{0}$ than the OXG4/hemin complex, as shown in Figure 4.

=0xacillin

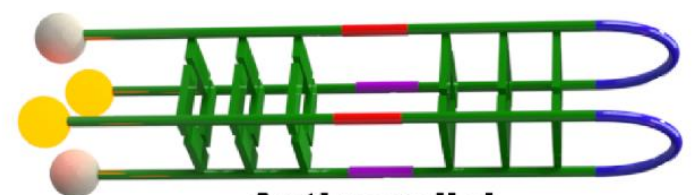

Anti-parallel

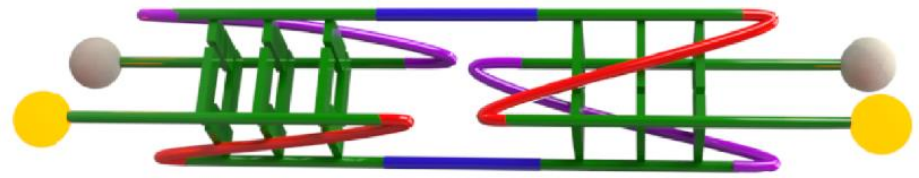

Parallel

$=$ Cy3.5

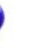


It was found that both the OX and OXG4 structures had a MIC of $0.5 \mu \mathrm{g} \mathrm{mL}{ }^{-1}$ (or $2.5 \mu \mathrm{M}$ OXG4) (data not shown). This indicated that the coupling $\mathrm{OX}$ to the $\mathrm{NH}_{2} \mathrm{G} 4$ ODN does not affect its antimicrobial activity profile. As a result, it showed promise to be used to investigate if the OXG4 structures could provide increased diffusion of the OX into the biofilm, without the need for added hydrogen peroxide. Singh et al. ${ }^{33}$ have previously found that $1 \mu \mathrm{g} \mathrm{mL}^{-1} \mathrm{OX}$ alone was unable to kill biofilm embedded cells. To this end, in order to perform biofilm diffusion studies, 1 $\mu \mathrm{g} \mathrm{mL} \mathrm{m}^{-1}$ of $\mathrm{OX}$ and $2.5 \mu \mathrm{M}$ OXG4 (equivalent to $1 \mu \mathrm{g} \mathrm{mL} \mathrm{m}^{-1}$ of free $\mathrm{OX}$ ) was chosen. In this manner, any antimicrobial affects observed from the OXG4/hemin complex could be attributed to the peroxidase-mimicking activity, rather than the activity of the $\mathrm{OX}$ alone.

First, OX $\left(1 \mu \mathrm{g} \mathrm{mL}^{-1}\right)$, hemin $(8 \mu \mathrm{M})$ and various concentrations of G4/hemin complexes (2 $\mu \mathrm{M}, 3 \mu \mathrm{M}, 4 \mu \mathrm{M}$ or $5 \mu \mathrm{M}$, with hemin at $8 \mu \mathrm{M}$ ) where tested on S. aureus ATCC 29213 (biofilm forming) biofilms to determine if they had an antimicrobial effect. Initially, S. aureus ATCC 29213 biofilms were established in 96-well plates and on silicone coupons using MHB with $20 \mathrm{~h}$ incubation at $37^{\circ} \mathrm{C}$. Following this the MHB was removed and then either $\mathrm{OX}\left(1 \mu \mathrm{g} \mathrm{mL} \mathrm{m}^{-1}\right)$, hemin $(8 \mu \mathrm{M})$ or $\mathrm{G} 4 /$ hemin complexes $(2 \mu \mathrm{M}, 3 \mu \mathrm{M}, 4 \mu \mathrm{M}$ or $5 \mu \mathrm{M}$, with hemin at $8 \mu \mathrm{M})$ in $\mathrm{MHB}$ (containing $0.5 \%(\mathrm{v} / \mathrm{v}) \mathrm{H}_{2} \mathrm{O}_{2}$ ) was added on top of each biofilm. The biofilm was then grown for a further $20 \mathrm{~h}$ to investigate antimicrobial activity and whether any persister cells remained after the initial growth and MHB removal (evidenced by further colony forming unit (CFU) described later). The wells and coupons were then washed with phosphate buffer saline (PBS) to remove any planktonic cells.

A LIVE/DEAD ${ }^{\mathrm{TM}}$ BacLight $^{\mathrm{TM}}$ Bacterial Viability Kit and CFSM were used to qualitatively confirm the presence of biofilms grown on silicone coupons (see Figure S1 for control). The validation of the biofilms by viable counts and CFSM paved the foundation for further 
experiments. The number of viable cells present in the biofilms was determined using CFU based viable count (see Figure S2 and S3). The control sample had a CFU of $\sim 10^{7} \mathrm{CFU} \mathrm{mL}^{-1}$ (Figure S2 and S3).

Figure 6 and Table $\mathrm{S} 1$ shows the percentage $\Delta \log _{10} \mathrm{CFU} \mathrm{mL} L^{-1}$ compared to the control (cells only in MHB).

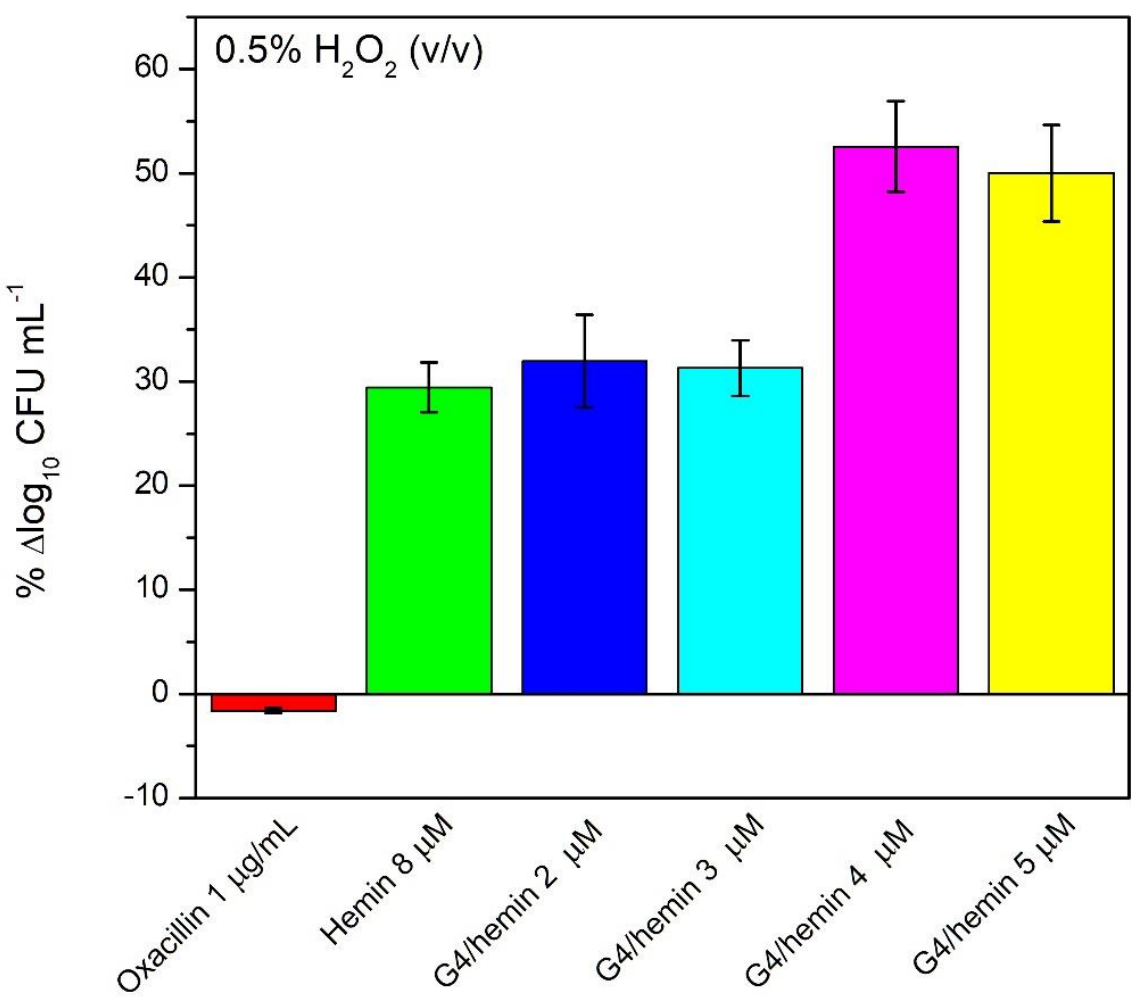

Figure 6. Bar graph showing the percentage $\Delta \log _{10} \mathrm{CFU} \mathrm{mL} \mathrm{m}^{-1}$ present in the S. aureus biofilms after $20 \mathrm{~h}$ incubation with $\mathrm{OX}\left(1 \mu \mathrm{g} \mathrm{mL} \mathrm{L}^{-1}\right)$, hemin $(8 \mu \mathrm{M})$ and $\mathrm{G} 4 /$ hemin complexes at $2 \mu \mathrm{M}, 3$ $\mu \mathrm{M}, 4 \mu \mathrm{M}$ and $5 \mu \mathrm{M}$ (with hemin at $8 \mu \mathrm{M}$ ) in a MHB containing $0.5 \% \mathrm{H}_{2} \mathrm{O}_{2}(\mathrm{v} / \mathrm{v})$. 
Figure 6 shows that the OX has only a slight effect on the cells within the biofilm, with a change in the number of cells of $-1.61 \pm 0.24 \% \Delta \log _{10} \mathrm{CFU} \mathrm{mL} \mathrm{m}^{-1}$ compared to the control. This is expected as $\mathrm{OX}\left(1 \mu \mathrm{g} \mathrm{mL} L^{-1}\right)$ is unable to enter or diffuse within biofilms. ${ }^{17}$ Another contributing factor is the presence of the $0.5 \% \mathrm{H}_{2} \mathrm{O}_{2}$, which may be degrading the antibiotic free in solution. In the presence of $0.5 \%(\mathrm{v} / \mathrm{v}) \mathrm{H}_{2} \mathrm{O}_{2}$, hemin $(8 \mu \mathrm{M})$ showed an effective antimicrobial activity on the cells inside of the biofilm, with a reduction of $29.43 \pm 2.39 \% \Delta \log _{10} \mathrm{CFU} \mathrm{mL} \mathrm{m}^{-1}$ of viable cells. This was not expected as hemin is thought to have low peroxidase-mimicking activity when by itself in solution. ${ }^{27}$ The G4/hemin at $2 \mu \mathrm{M}$ and $3 \mu \mathrm{M}$ showed similar results to hemin alone, however, once the concentration of the $\mathrm{G} 4 / \mathrm{hemin}$ reached $4 \mu \mathrm{M}$ and $5 \mu \mathrm{M}$ the effectiveness to reduce the number of viable $S$. aureus cells in the biofilm was doubled to $50.02 \pm 4.64 \% \Delta \log _{10} \mathrm{CFU} \mathrm{mL} \mathrm{mL}^{-1}$ and 52.58 $\pm 4.36 \% \Delta \log _{10} \mathrm{CFU} \mathrm{mL}{ }^{-1}$, respectively.

Overall, these results are very positive, showing that hemin alone has an antimicrobial affect, but this is greatly increased by its complexation with $\mathrm{G} 4$ structures when $\mathrm{H}_{2} \mathrm{O}_{2}$ is present in the MHB. Further, these structures are able to enter and diffuse through the biofilm, unlike OX alone. ${ }^{33}$ It is known that $\mathrm{G} 4 /$ hemin complexes within the body are able to react with peroxide species and subsequently cell components (e.g., cell walls) and damage cells in much the same manner as the SCN-peroxidase- $\mathrm{H}_{2} \mathrm{O}_{2}$ systems. ${ }^{27}$ Therefore, it was next investigated if it was possible for the G4/hemin complex to have similar effects without the addition of the $0.5 \% \mathrm{H}_{2} \mathrm{O}_{2}$. Further investigation is required to determine how the G4/hemin complexes are able to penetrate and the exact mechanisms.

To improve the antimicrobial activity of the G4/hemin complexes, the impact of OX coupled G4/hemin complexes on the S. aureus biofilms was studied. In order to keep analysis consistent, the concentration of the OXG4 was calculated in terms of OX concentration assuming a near 
$\sim 100 \%$ coupling of OX to G4. Therefore, a stock solution of $5 \mu$ M OXG4 was made up by diluting the purified OXG4 in MHB. $10 \mu \mathrm{L}$ of the $5 \mu \mathrm{M}$ OXG4 was added to a 96-well plate and $10 \mu \mathrm{L}$ of MHB broth was added. To this end OX $\left(1 \mu \mathrm{g} \mathrm{mL} \mathrm{m}^{-1}\right)$, hemin $(8 \mu \mathrm{M}), \mathrm{G} 4(50 \mu \mathrm{M})$, G4/hemin complex $(50 \mu \mathrm{M})$, OXG4 $(2.5 \mu \mathrm{M})$ and OXG4/hemin complex $(2.5 \mu \mathrm{M})$, were tested for antimicrobial activity against S. aureus ATCC 29213 biofilms in a similar manner to the previous biofilm studies (Figure 6). Since the peroxide was shown affect the OX in a negative way, based on the increase in the $\Delta \log _{10} \mathrm{CFU} \mathrm{mL} L^{-1}\left(-1.61 \pm 0.24 \% \Delta \log _{10} \mathrm{CFU} \mathrm{mL} L^{-1}\right)$ the remaining experiments were performed without the aid of peroxide. It was hypothesized that the natural peroxide species produced within the biofilms would facilitate peroxidase-mimicking activity of the G4/hemin complexes.

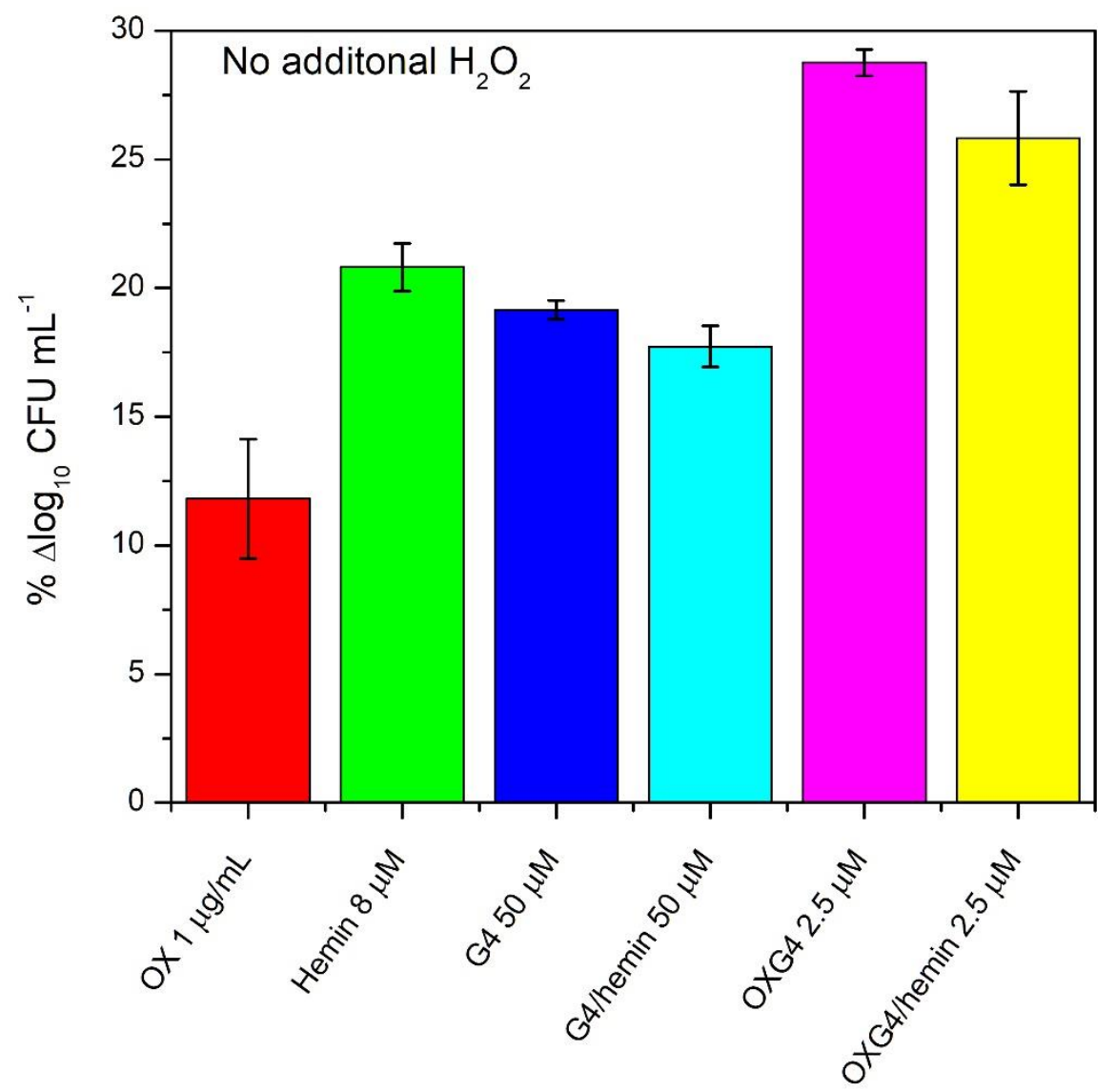


Figure 7. Bar graph showing the percentage $\Delta \log _{10} \mathrm{CFU} \mathrm{mL} \mathrm{L}^{-1}$ present in the $S$. aureus biofilms after $20 \mathrm{~h}$ incubation folded structures of $\mathrm{OX}\left(1 \mu \mathrm{g} \mathrm{mL} \mathrm{L}^{-1}\right)$, hemin $(8 \mu \mathrm{M}), \mathrm{G} 4(50 \mu \mathrm{M})$, G4/hemin complex $(50 \mu \mathrm{M})$, OXG4 $(2.5 \mu \mathrm{M})$ and OXG4/hemin complex $(2.5 \mu \mathrm{M})$.

Figure 7 and Table S2 show that the OXG4 and OXG4/hemin complex had the largest effect in regard to the reduction in the number of viable $S$. aureus cells, with a reduction of $28.76 \pm 0.51 \%$ $\Delta \log _{10} \mathrm{CFU} \mathrm{mL} \mathrm{mL}^{-1}$ and $25.82 \pm 1.18 \% \Delta \log _{10} \mathrm{CFU} \mathrm{mL} \mathrm{m}^{-1}$, respectively. This indicates that the OX attached to the G4 is having improved antibiotic activity compared to the G4 alone or G4/hemin complex. This is hypothesized to be due to the lack of endogenous peroxide species in the MHB and biofilm. As expected, OX had the lowest reduction of viable cells at $11.43 \pm 2.32 \% \Delta \log _{10}$ CFU mL ${ }^{-1}$, again indicating that $\mathrm{OX}$ is not able to readily cross the biofilm. However, it should be noted that unlike Figure. 6, where there was an increase in $-1.61 \pm 0.24 \% \Delta \log _{10} \mathrm{CFU} \mathrm{mL} \mathrm{mL}^{-1}$, there was a decrease in the $\Delta \log _{10} \mathrm{CFU} \mathrm{mL} \mathrm{m}^{-1}$.

Clearly, this work indicates that G4/hemin complexes alone can reduce $S$. aureus cell viability in biofilms in the presence of $\mathrm{H}_{2} \mathrm{O}_{2}$. Importantly by coupling these structures with the antibiotic OX, an increase in diffusion into the biofilm allows for further improved cell death compared to OX alone. This shows that there is a possibility to use DNA as a possible diffusion facilitator for other coupled drugs.

\section{CONCLUSION}


This work details a new antimicrobial system for combating S. aureus biofilm forming bacteria. Using a TMB assay and MIC analysis it was shown that OX could effectively be coupled to an amine-functionalized G-rich ODN. Preliminary studies of the unique G4/hemin complex systems, in the presence of $0.5 \%(\mathrm{v} / \mathrm{v}) \mathrm{H}_{2} \mathrm{O}_{2}$, showed a reduction in biofilm cells of up to $52.02 \pm 4.64 \%$ $\Delta \log \mathrm{CFU} \mathrm{mL} \mathrm{mL}^{-1}$ at $5 \mu \mathrm{M}$ compared to hemin alone, showing the $\mathrm{G} 4$ was able to penetrate and diffuse into the biofilms. The antimicrobial activity of the OXG4lhemin complex, without peroxide, was shown to be over twice as effective as OX alone, indicating that the G4 played an active role as a diffusion facilitator of OX into the biofilm matrix. This work shows promise for increasing the effectiveness of antibiotics using unique DNA nanostructuring assembles, such as the G4 complexes used here. This system may provide a better candidate for peroxidase-like antimicrobial systems into the future.

\section{SUPPORTING INFORMATION}

The following files are available free of charge. Provides information on fluorescence confocal scanning microscope image of S. aureus ATCC 29213 biofilms and CFU data.

\section{ACKNOWLEDGEMENT}

The authors wish to thank the Australian Research Council (ARC) for Future Fellowship funding (FT130100211) and the CSIRO for KL's Julius Career Award. 


\section{ABBREVIATIONS}

G4, G-Quadruplex; OX, oxacillin; OXG4, oxacillin coupled G-quadruplex; ODN, oligodeoxynucleotide; SCN, thiocyanate; $\mathrm{H}_{2} \mathrm{O}_{2}$, hydrogen peroxide; G-rich, guanine-rich; Gquartets, guanine-quartets; Fe, iron; TMB, 3,3,5,5-tetramethylbenzidine; MIC, minimum inhibitory concentrations; BSA, bovine serum albumin; EDC, 1-ethyl-3-(3dimethylaminopropyl)carbodiimide; nts, nucleotides; PAGE, polyacrylamide electrophoresis; MHB, Mueller-Hinton Broth; CFU, colony forming unit; PBS, phosphate buffer saline; CSFM, confocal fluorescence scanning microscopy.

\section{REFERENCES}

(1) Costerton, J. W. Introduction to Biofilm. In International Journal of Antimicrobial Agents; Elsevier. 1999, 11, 217-221.

(2) Høiby, N.; Bjarnsholt, T.; Givskov, M.; Molin, S.; Ciofu, O. Antibiotic Resistance of Bacterial Biofilms. Int. J. Antimicrob. Agents. 2010, 35 (4), 322-332.

(3) Santos, A. P. A.; Watanabe, E.; Andrade, D. de. Biofilm on Artificial Pacemaker: Fiction or Reality? Arq. Bras. Cardiol. 2011, 97 (5), e113-20.

(4) Neopane, P.; Nepal, H. P.; Shrestha, R.; Uehara, O.; Abiko, Y. In Vitro Biofilm Formation by Staphylococcus Aureus Isolated from Wounds of Hospital-Admitted Patients and Their Association with Antimicrobial Resistance. Int. J. Gen. Med. 2018, 11, 25-32.

(5) Ciofu, O.; Rojo-Molinero, E.; Macià, M. D.; Oliver, A. Antibiotic Treatment of Biofilm Infections; 2017, 125, 304-319. 
(6) Costerton, J. W.; Geesey, G. G.; Cheng, K. J. How Bacteria Stick. Sci. Am. 1978, 238 (1), 86-95.

(7) Costerston. Biofouling and Biocorrosion in Industrial Water Systems - CRiM 200531 213-232.Pdf. In International Workshop on Industrial Biofouling and Biocorrosion,; Lewis Publishers, 1990, 297.

(8) Metzler, A. Developing a Crystal Violet Assay to Quantify Biofilm Production Capabilities of Staphylococcus Aureus. 2016, 1-15.

(9) Costerton, J. W.; Stewart, P. S.; Greenberg, E. P. Bacterial Biofilms: A Common Cause of Persistent Infections. Science (80-. ). 1999, 284 (5418), 1318-1322.

(10) Montanaro, L.; Poggi, A.; Visai, L.; Ravaioli, S.; Campoccia, D.; Speziale, P.; Arciola, C. R. Extracellular DNA in Biofilms. International Journal of Artificial Organs. 2011, 824-831.

(11) Donlan, R. M. Biofilms: Microbial Life on Surfaces. Emerg. Infect. Dis. 2002, 8 (9), 881890.

(12) Lewis, K. Persister Cells and the Riddle of Biofilm Survival. Biochemistry (Moscow). 2005, 267-274.

(13) Lewis, K. Persister Cells, Dormancy and Infectious Disease. Nature Reviews Microbiology. 2007, 48-56.

(14) Rolain, J. M.; Abat, C.; Jimeno, M. T.; Fournier, P. E.; Raoult, D. Do We Need New Antibiotics? Clin. Microbiol. Infect. 2016, 22 (5), 408-415. 
(15) Monzon, M.; Oteiza, C.; Leiva, J.; Amorena, B. Synergy of Different Antibiotic Combinations in Biofilms of Staphylococcus Epidermidis. J. Antimicrob. Chemother. 2001, 48 (6), 793-801.

(16) Kalishwaralal, K.; BarathManiKanth, S.; Pandian, S. R. K.; Deepak, V.; Gurunathan, S. Silver Nanoparticles Impede the Biofilm Formation by Pseudomonas Aeruginosa and Staphylococcus Epidermidis. Colloids Surfaces B Biointerfaces 2010, 79 (2), 340-344.

(17) Azam, A.; Ahmed, F.; Arshi, N.; Chaman, M.; Naqvi, A. H. One Step Synthesis and Characterization of Gold Nanoparticles and Their Antibacterial Activities against E . Coli ( ATCC 25922 Strain ). Int. J. Theor. Appl. Sci. 2009, 1 (2), 1-4.

(18) Adams, C. P.; Walker, K. A.; Obare, S. O.; Docherty, K. M. Size-Dependent Antimicrobial Effects of Novel Palladium Nanoparticles. PLoS One 2014, 9 (1), e85981.

(19) Sena-Vélez, M.; Redondo, C.; Graham, J. H.; Cubero, J. Presence of Extracellular DNA during Biofilm Formation by Xanthomonas Citri Subsp. Citri Strains with Different Host Range. PLoS One 2016, 11 (6), e0156695.

(20) Chandler, J. D.; Day, B. J. Thiocyanate: A Potentially Useful Therapeutic Agent with Host Defense and Antioxidant Properties. Biochem. Pharmacol. 2012, 84 (11), 1381-1387.

(21) Amar K, C. Iodine, Thiocyanate and the Thyroid. Biochem. Pharmacol. Open Access 2015, $04(03), 1-6$.

(22) Hardin, C. C.; Perry, A. G.; White, K. Thermodynamic and Kinetic Characterization of the Dissociation and Assembly of Quadruplex Nucleic Acids. Biopolymers. 2000, 147-194. 
(23) Sattin, G.; Artese, A.; Nadai, M.; Costa, G.; Parrotta, L.; Alcaro, S.; Palumbo, M.; Richter, S. N. Conformation and Stability of Intramolecular Telomeric G-Quadruplexes: Sequence Effects in the Loops. PLoS One 2013, 8 (12), e84113.

(24) Bhattacharyya, D.; Mirihana Arachchilage, G.; Basu, S. Metal Cations in G-Quadruplex Folding and Stability. Front. Chem. 2016, 4, 38.

(25) Loh, Q.; Lim, T. S. DNA G-Quadruplex as a Reporter System for Sensor Development. In Nucleic Acids - From Basic Aspects to Laboratory Tools; 2016, ISBN 978-953-51-2264-7.

(26) Lane, A. N.; Chaires, J. B.; Gray, R. D.; Trent, J. O. Stability and Kinetics of G-Quadruplex Structures. Nucleic acids research. 2008, 5482-5515.

(27) Cheng, X.; Liu, X.; Bing, T.; Cao, Z.; Shangguan, D. General Peroxidase Activity of GQuadruplex-Hemin Complexes and Its Application in Ligand Screening. Biochemistry 2009, 48 (33), 7817-7823.

(28) Traylor, T. G.; Kim, C.; Fann, W. P.; Perrin, C. L. Reactions of Hydroperoxides with Iron(III) Prophyrins: Heterolytic Cleavage Followed by Hydroperoxide Oxidation. Tetrahedron 1998, 54 (28), 7977-7986.

(29) Chen, J.; Guo, Y.; Zhou, J.; Ju, H. The Effect of Adenine Repeats on G-Quadruplex/Hemin Peroxidase Mimicking DNAzyme Activity. Chem. - A Eur. J. 2017, 23 (17), 4210-4215.

(30) Aumiller, W. M.; Davis, B. W.; Hatzakis, E.; Keating, C. D. Interactions of Macromolecular Crowding Agents and Cosolutes with Small-Molecule Substrates: Effect on 
Horseradish Peroxidase Activity with Two Different Substrates. J. Phys. Chem. B 2014, 118 (36), $10624-10632$.

(31) Sun, H.; Li, X.; Li, Y.; Fan, L.; Kraatz, H. B. A Novel Colorimetric Potassium Sensor Based on the Substitution of Lead from G-Quadruplex. Analyst 2013, 138 (3), 856-862.

(32) Yang, X.; Fang, C.; Mei, H.; Chang, T.; Cao, Z.; Shangguan, D. Characterization of GQuadruplex/Hemin Peroxidase: Substrate Specificity and Inactivation Kinetics. Chem. - A Eur. J. 2011, 17 (51), 14475-14484.

(33) Singh, R.; Ray, P.; Das, A.; Sharma, M. Penetration of Antibiotics through Staphylococcus Aureus and Staphylococcus Epidermidis Biofilms. J. Antimicrob. Chemother. 2010, 65 (9), 19551958.

(34) Vorlíčková, M.; Bednářová, K.; Kejnovská, I.; Kypr, J. Intramolecular and Intermolecular Guanine Quadruplexes of DNA in Aqueous Salt and Ethanol Solutions. Biopolymers 2007, 86 (1), $1-10$.

(35) CLSI. Performance Standards for Antimicrobial Susceptibility Testing: 26th Informational Supplement, Document M100-S26. Clin. Lab. Stand. Inst. 2016.

(36) Shapiro, D. J. Quantitative Ethanol Precipitation of Nanogram Quantities of DNA and RNA. Anal. Biochem. 1981, 110 (1), 229-231.

(37) Fenati, R. A.; Connolly, A. R.; Ellis, A. V. Single Nucleotide Polymorphism Discrimination with and without an Ethidium Bromide Intercalator. Anal. Chim. Acta 2017, 954, $121-128$. 
(38) Li, T.; Wang, E.; Dong, S. Base-Pairing Directed Folding of a Bimolecular G-Quadruplex: New Insights into G-Quadruplex-Based DNAzymes. Chem. - A Eur. J. 2009, 15 (9), 2059-2063.

(39) Qu, Y.; Istivan, T. S.; Daley, A. J.; Rouch, D. A.; Deighton, M. A. Comparison of Various Antimicrobial Agents as Catheter Lock Solutions: Preference for Ethanol in Eradication of Coagulase-Negative Staphylococcal Biofilms. J. Med. Microbiol. 2009, 58 (4), 442-450. 


\section{TABLE OF CONTENTS}

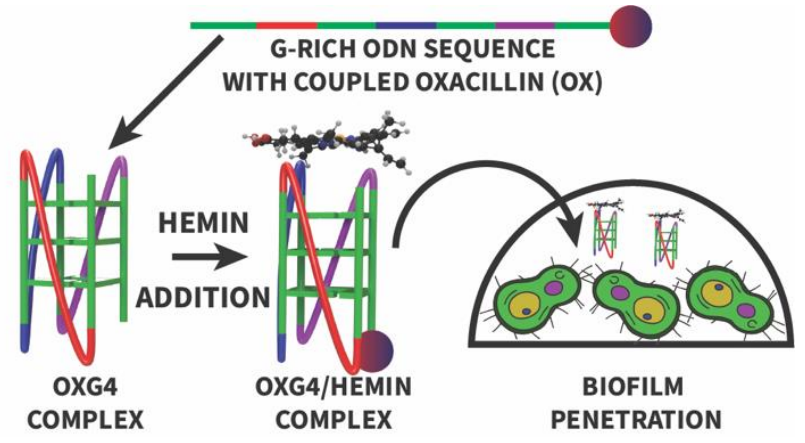

